\title{
Effects of changes in dietary habits on colorectal cancer incidence in twenty countries from four continents during the period 1971-2002
}

\author{
Luis M. Béjar ${ }^{1,3}$, Miguel Gilii ${ }^{1,2,3}$, Beatriz Infantes ${ }^{3}$ and Pamela F. Marcott ${ }^{1}$ \\ ${ }^{1}$ Department of Preventive Medicine and Public Health. Universidad de Sevilla. Spain. ${ }^{2}$ Service of Preventive \\ Medicine and Public Health. Hospital Virgen Macarena. Sevilla, Spain. ${ }^{3}$ Group of Clinical Epidemiology. \\ Universidad de Sevilla. Spain
}

\begin{abstract}
Introduction: the incidence of colorectal cancer is one of the highest on a global level. Many epidemiological studies have identified risk and protective factors, many of which have a behavioral component and, therefore, are potentially avoidable or subject to modification. This study investigated the incidence rates of colorectal cancer by gender in twenty different countries, taking into account the dietary habits of the habitants of each country.

Material and methods: adjusted incidence rates, according to gender, were obtained for each country from the International Agency for Research on Cancer during the period 1971-2002. Annual per capita consumption data of the different dietary variables were obtained for the period 1961-2007 from the Food and Agriculture Organization of the United Nations. Pearson's correlation coefficients were calculated comparing incidence rates according to gender with different dietary variable using ten-year delay intervals.

Results: there is an important variation in trends of colorectal cancer incidence worldwide which were found to be related with the dietary habits of each country.

Discussion: based on the trends observed, each country was classified into one of four different situations based on the range of values of their incidence rates and linear trends observed. Due to the potential of primary prevention programs for colorectal cancer and to the delay between changes in the exposure to risk and protective factors and the effects on the incidence of this tumor, the application of legislative and educational measures promoting a healthy diet has become an urgent issue to stop the increasing tendency of colorectal cancer reported worldwide.
\end{abstract}

Key words: Alcohol drinking. Colorectal neoplasms. Diet. Epidemiology. Incidence.

Received: 14-02-2011.

Accepted: 29-04-2011.

Correspondence: Luis M. Béjar. Departamento de Medicina Preventiva y Salud Pública. Facultad de Medicina. Avenida Sánchez-Pizjuán, s/n. 41009 Sevilla.

e-mail:1mbprado@us.es
Béjar LM, Gili M, Infantes B, Marcott PF. Effects of changes in dietary habits on colorectal cancer incidence in twenty countries from four continents during the period 1971-2002. Rev Esp Enferm Dig 2011; 103: 519-529.

\section{INTRODUCTION}

The latest available data from the Cancer Registries supervised by the International Agency for Research on Cancer (IARC), show that, globally, in men, colorectal cancer is the second most incident tumor in Australia, China, Israel, Japan, New Zealand, Norway and Sweden; the third in Canada, Costa Rica, England, France, Germany, Italy, Spain, Thailand and USA; the fourth in Brazil and Colombia; the fifth in India and the sixth in Ecuador. In women, this tumor has the second highest incidence in Australia, China, France, Germany, Israel, Italy, Japan, New Zealand, Norway, Spain, Sweden and USA; the third in Brazil, Canada, England and India; the fourth in Colombia, Costa Rica and Thailand and the eighth in Ecuador (1).

Variations in colorectal cancer incidence in these twenty countries from four continents are considerable. In 2002, in men, differences in colorectal cancer incidence rates adjusted to worldwide population per 100,000 inhabitants between India (lowest incidence) and Germany (highest incidence) is 47.5 points, which represents a variation of $819.0 \%$. The same comparison in women shows a difference of 33.1 points between India and New Zealand (lowest and highest incidence, respectively), which represents a variation of $788.1 \%$.

Major variation in incidence of colorectal cancer in different geographical regions is probably due to the different level of exposure to risk and protective factors related to colorectal cancer (2). It is noteworthy that many of these factors are associated with behavioral practices, thus they are potentially avoidable or subject to modification (3-8). 
There are excellent reviews that analyze in a detailed manner the diverse behavioral factors related with colorectal cancer $(9,10)$. Risk factors include alcohol $(11,12)$, red meat consumption (11,13-16), low vegetable and folate intake (17,18), smoking (19-21), sedentary lifestyle, overweight, obesity (22-24), diabetes (25) and short duration and poor quality of sleep (26); protective factors include fish consumption $(14,15)$, hormone replacement therapy $(27,28)$, oral contraceptive use $(29)$, calcium intake (30), higher bone mass levels (31) and physical exercise (11,32-34). The results from several epidemiological studies are inconsistent concerning the effects of dietary fiber intake (35-39). A meta-analysis including thirteen case-control studies showed that animal fat was not related with colorectal cancer risk after adjustment of total energy (40) and most cohort studies do not support a causal association between this factor and colorectal cancer (41).

Some studies have demonstrated the influence of changes in the exposure to these factors on the incidence of this kind of tumor (3-8).

The aim of this study is to analyze the evolution of the incidence of colorectal cancer in twenty countries from four continents in the last decades and its relationship with changes in the dietary habits of the population.

\section{MATERIAL AND METHODS}

Annual colorectal cancer incidence rates adjusted to worldwide population per 100,000 inhabitants -codes C18$\mathrm{C} 21,10^{\text {th }}$ revision of the International Classification of Diseases (ICD)- in men and women were obtained from the IARC for the period 1971-2002. Rates were compiled during the aforementioned period starting with the first year with accessible data in the Cancer Registries of each country until the year 2002, which is the last year with accessible data at the time of this study (up to October, 20 $0^{\text {th }} 2010$ ). Spain is the only exception, which has only been registered until the year 2000.

Data from the IARC correspond to different types of Cancer Registries. Local Cancer Registries cover specific areas in each country such as in Germany (Saarland) in Europe; Brazil (Goiania), Colombia (Cali) and Ecuador (Quito) in America; and Thailand (Chiang Mai) in Asia. Central Cancer Registries gather and homogenize the information from several Local Cancer Registries, such as in England (Birmingham and West Midlands Region, Merseyside and Cheshire, North Western, Oxford and Yorkshire), France (Bas-Rhin, Calvados, Doubs, HautRhin, Herault, Isere, Somme and Tarn), Italy (Florence, Lombardy Varese Province, Modena, Parma, Ragusa Province, Romagna and Torino) and Spain (Granada, Murcia, Navarra, Tarragona and Zaragoza) in Europe; Canada (Alberta, British Columbia, Manitoba, New Brunswick, Newfoundland, Nova Scotia, Ontario, Prince Edward Island and Saskatchewan) and USA (Atlanta, Connecticut,
Detroit, Iowa, Los Angeles, New Mexico, New Orleans, San Francisco, Seattle and Utah) in America; China (Hong Kong and Shanghai), India (Chennai and Mumbai) and Japan (Miyagi Prefecture, Osaka Prefecture and Yamagata Prefecture) in Asia; and Australia (New South Wales, South, Tasmania, Victoria and Western) in Oceania. Finally National Cancer Registries cover the whole population of the country, such as in Norway and Sweden in Europe; Costa Rica in America; Israel (Jews) in Asia; and New Zealand in Oceania (1).

Annual per capita data of alcohol (in liters), cereals, fruit, vegetable, legume, poultry, red meat and fish (in kilograms) consumption for the period 1961-2007 were obtained from the data published (up to October, 20 $0^{\text {th }} 2010$ ) by the Food and Agriculture Organization of the United Nations (FAO) (42). The linear regression coefficients were calculated for each dietary variable. Consumption data are shown during the period of study for each country and in ten-year intervals.

Pearson's correlation coefficients were calculated by gender using ten-year delay intervals, i.e. annual colorectal cancer incidence rates adjusted to worldwide population per 100,000 inhabitants in men and women are correlated to annual per capita consumption data in the previous ten years, according to the available period in each country studied. The statistical analyses were done using Stata 10.0 StataCorp LP, Texas, USA.

\section{RESULTS}

Annual colorectal cancer incidence rates are shown for men and women in Europe for England, France, Germany, Italy, Norway, Spain and Sweden; in America for Brazil, Canada, Colombia, Costa Rica, Ecuador and USA; in Asia for China, India, Israel, Japan and Thailand; and in Oceania for Australia and New Zealand, according to the available period in each country (Table I).

In England, France, Germany, Italy, Norway, Spain, Sweden (Europe); Canada, Costa Rica, USA (America); China, India, Japan (Asia); Australia and New Zealand (Oceania) incidence rates in men are higher than in women during the complete period studied for each country. In Israel (Asia) incidence rates in men are higher than in women except in the year 1977. Only in Brazil, Colombia, Ecuador (America) and Thailand (Asia) are incidence rates in women higher than in men for more than one year; in Brazil in eleven of the fifteen years studied, in Colombia in ten of the twenty years, in Ecuador in fourteen of the eighteen years and in Thailand in five of the twenty years.

In men, incidence rates follow an increasing linear trend in all countries during the period of study except for in France (Europe); USA (America); and New Zealand (Oceania). In women, there is a decreasing linear trend in England, France (Europe); Canada, USA (America); and New Zealand (Oceania), while the trend is increasing in the remaining countries. 
ต ำ 守 ฝ่

ஸ்

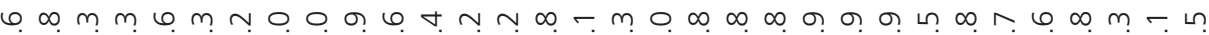

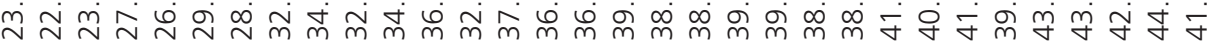

ก

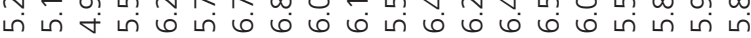

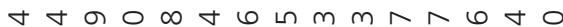

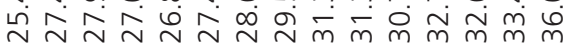

t八

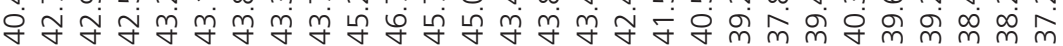

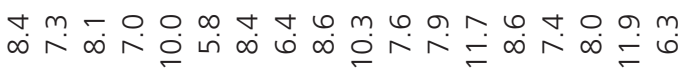

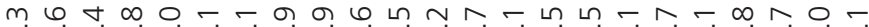
드으

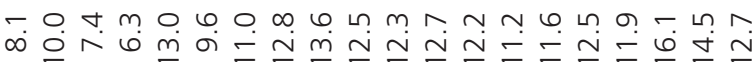

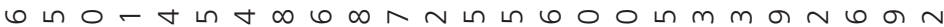
শ্่ে

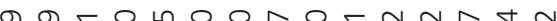

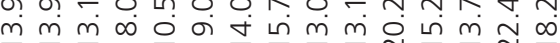

$m m \wedge-\infty \circ n-m a m 0 \wedge m \wedge 96 \wedge \wedge 60 \wedge \wedge-m 09 \wedge 6 m 06$

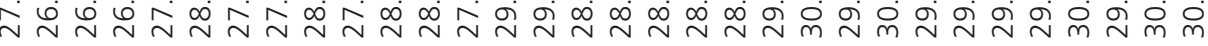

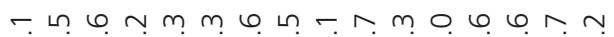

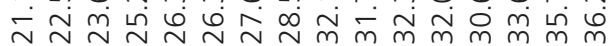

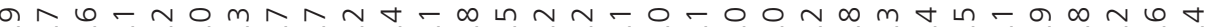

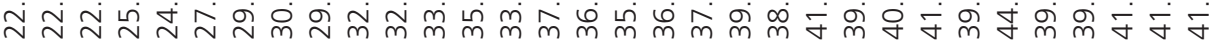
เก $\sigma \nabla-6 \wedge \forall \sim$ เ

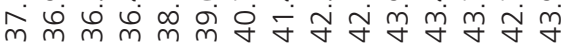

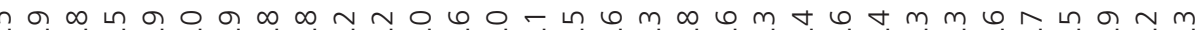
宛

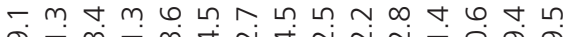

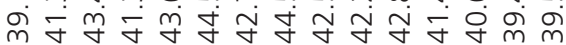

$\wedge+\forall 0 N N-6 m \wedge \sim \min 6 \sigma \wedge N-$

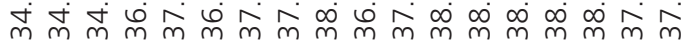

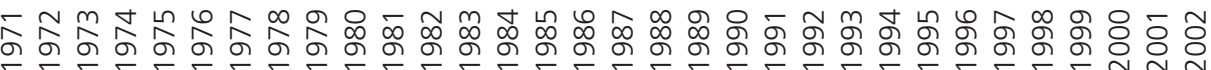




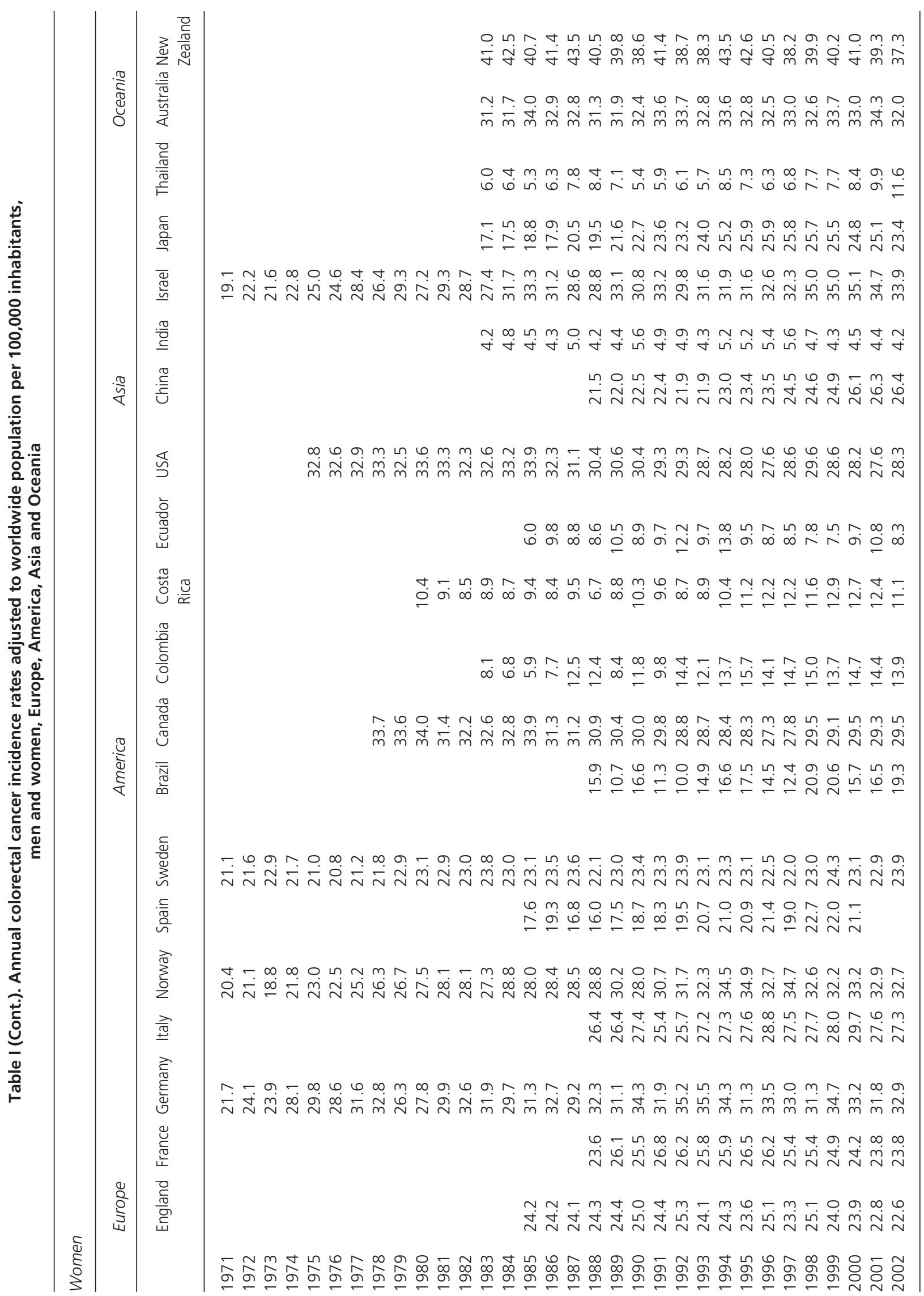


In Germany, Italy, Norway, Spain, Sweden (Europe); Brazil, Colombia, Costa Rica, Ecuador (America); China, India, Israel, Japan, Thailand (Asia); and Australia (Oceania), incidence rates in both genders show an increasing tendency with a greater slope in men than in women. Exceptions to this are seen in Colombia where the inverse situation is observed and in Thailand where linear trends are approximately parallel between genders.

Annual per capita consumption of alcohol, cereals, fruits, vegetables, legumes, poultry, red meat and fish and their linear regression coefficients are shown in table II.

In Europe, food of vegetable origin is the most consumed, with cereals, fruits and vegetables at the forefront. During specific periods in England, France, Germany, Norway and Sweden, red meat is the third most consumed food. Conversely, legume intake is minimal, being the least consumed food in all countries studied. Among food of animal origin, red meat is the most consumed, much more than poultry or fish, in all countries except for Norway, where red meat and fish intake levels are similar. During the period of study, there is an increasing linear trend in food of vegetable origin (cereals, fruits, vegetables), except for vegetables in France and cereals in Italy and Spain. Legume intake remains practically the same. Concerning red meat intake, an increasing linear trend is observed in all countries except for England and Norway. Similarly, poultry and fish consumption show an increasing linear trend in all countries, except for fish intake in England. In Norway, alcohol intake almost tripled during the period of study and in France and Italy, it decreased.

In America, food of vegetable origin is the most consumed, with cereals and fruits at the forefront. In Ecuador, fruit consumption is the highest above all other food during the period of study. In Brazil, Colombia and Costa Rica, cereals and fruits alternate as the most consumed food throughout the period of study. Legume consumption is the lowest in all analyzed countries, although in Brazil, legume consumption is very high during the period of study, with levels higher than twenty $\mathrm{kg} /$ person during several years. Regarding food of animal origin, red meat is the most consumed followed by poultry and fish. During the last few years, red meat and poultry consumption have reached similar levels in countries such as Colombia and Costa Rica. An increasing linear trend is observed in consumption of food of vegetable origin (cereals, fruits and vegetables) in all countries except for fruits and vegetables in Ecuador. During the period of study, legume consumption remains constant in Costa Rica and USA, decreases markedly in Ecuador and Brazil (in spite of high levels of legume consumption in Brazil) and increases in Canada and Colombia. Concerning red meat consumption, an increasing linear trend is observed in Brazil (markedly), Costa Rica and Ecuador while a decreasing trend is observed in Canada (notably), Colombia and USA. On the other hand, increasing linear trends are observed in poultry consumption in all countries. With regards to fish consumption, notable increases are only observed in Canada and USA. Alcohol intake slightly increases in all countries and, although it has been mild in most of them, in Brazil alcohol intake has almost tripled during the period of study.

In Asia, food of vegetable origin is the most consumed, although in Japan, fish intake is high, being the third most consumed food after cereals and vegetables but before fruits. In India, Japan and Thailand, the most consumed food during the period of study are cereals. In China, vegetable consumption has overtaken cereals, although only in the last few years. In Israel, cereals, fruits and vegetables alternate as the most consumed foods. Legume consumption is the lowest in all countries studied, although in India, legume consumption is very high during the period of study, with levels higher than twenty $\mathrm{kg} /$ person during several years. Regarding food of animal origin, in China the most consumed is red meat followed by fish and poultry; in Israel, poultry is the most consumed followed by red meat and fish; in India, Japan and Thailand the most consumed is fish followed by red meat and poultry. Regarding consumption of food of vegetable origin (cereals, fruits and vegetables), an increasing linear trend is observed in China and India, with fruit consumption decreasing in Israel and cereals and vegetable consumption decreasing in Japan and Thailand. Legume consumption remains approximately the same in Japan and Thailand, decreases in China and India and slightly increases in Israel. The linear trend regarding intake of food of animal origin is mildly increasing in China with respect to red meat, fish and poultry consumption; in India, it is slightly increasing for fish while remaining essentially the same for red meat and poultry; in Israel, poultry consumption increases notably, while red meat and fish consumption only slightly increase; in Japan, red meat and poultry consumption mildly increase, while fish consumption slightly increases, although decreases in the last few years; in Thailand, fish consumption increases markedly, poultry consumption mildly and red meat only slightly. Regarding alcohol intake, the linear tendency remains approximately constant in India and Israel and increases slightly in China, Japan and Thailand, where alcohol intake increases nine times during the period of study.

In Oceania, the most consumed food during the latest years is food of vegetable origin, especially fruits and vegetables. In Australia, red meat was the most consumed food during the late 70's, while in New Zealand it was the most consumed during two decades, the 60's and the 70's. Conversely, legumes are the least consumed in both countries. Regarding food of animal origin, red meat consumption is notably higher than that of poultry and fish. A linear trend in consumption of food of vegetable origin (cereals, fruits and vegetables) is increasing in both countries, except for cereals in Australia. Legume consumption remains about the same during the period of study. Concerning red meat consumption, the linear trend is decreasing in both countries. The linear trends of poultry and fish consumption are both positive, but with a higher slope in the case of poultry. Regarding alcohol intake, the linear trend remains constant during the period of study, with slight increases in the 70's and 80's and reaching values similar to those of the 60's in both countries. 


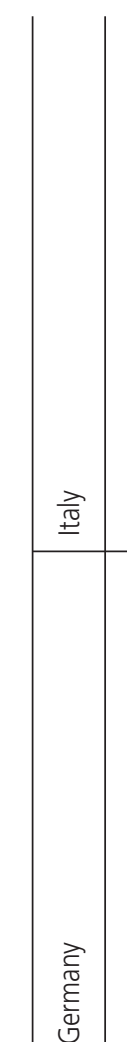

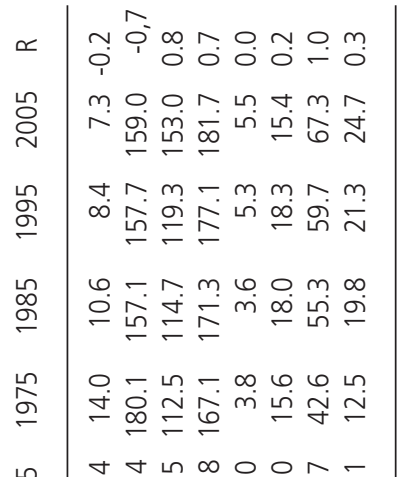

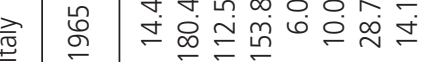

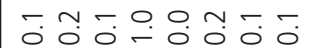

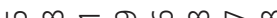

융 윰

命

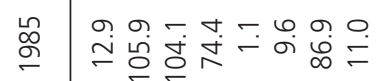

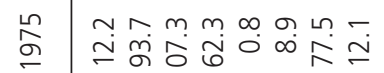

हैं

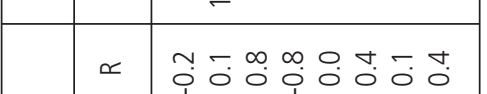

늄

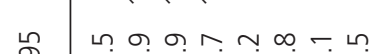

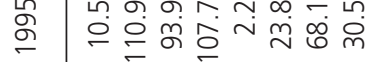

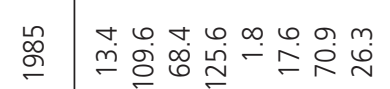

吕

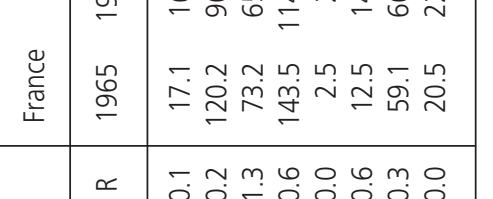

n $00-000$

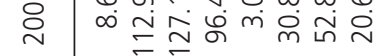

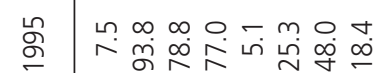

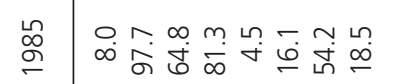

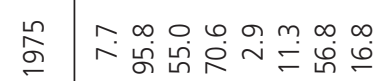

员

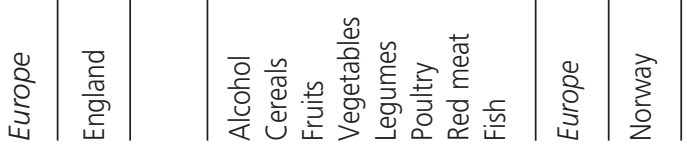

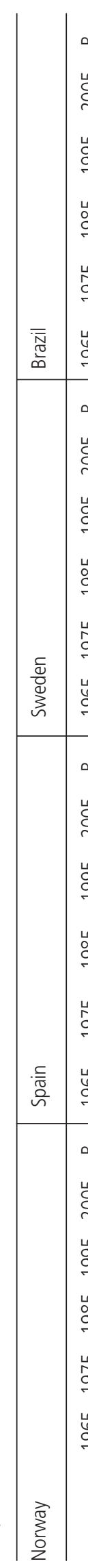

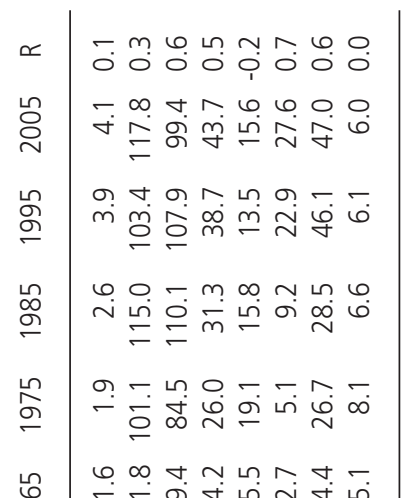

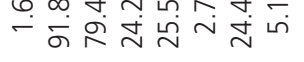

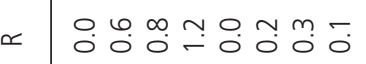

늄

능 ஸ̣

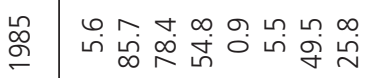

느의

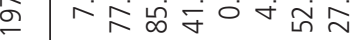

ก

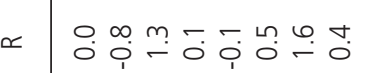

号

岗

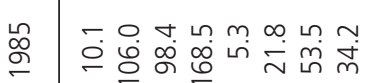

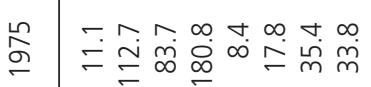

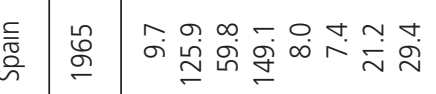

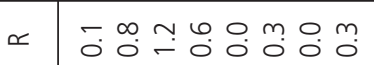

ᄂ $\quad \infty \wedge \varphi$ ต $m$ m.

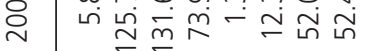

นn m

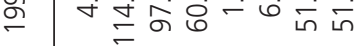

மீ

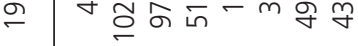

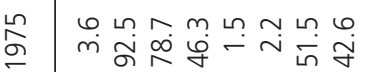

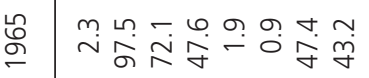

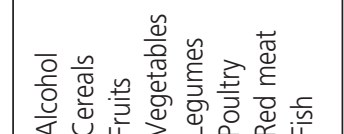

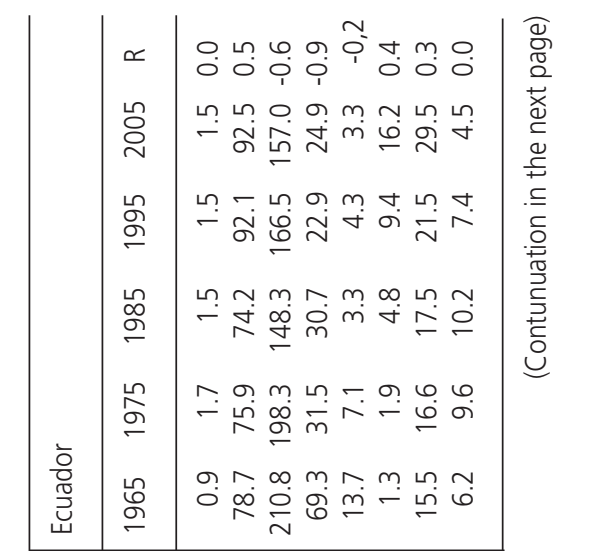

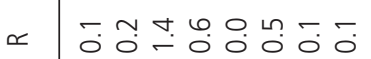

经 $\quad$ m 0 -

으

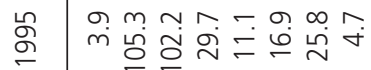

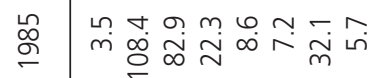

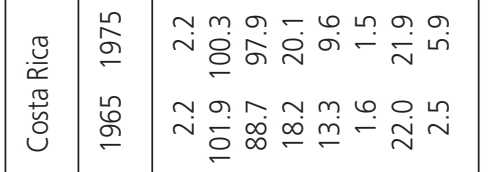

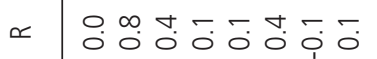

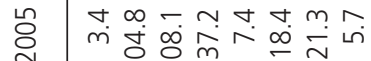

ก $\sigma-\sim \omega \sigma-\infty$

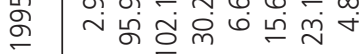

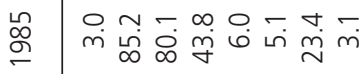

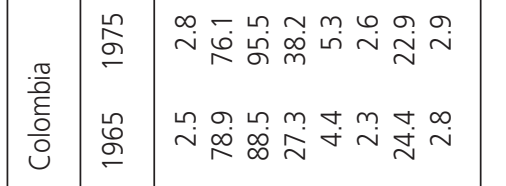

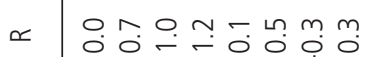

능 $\wedge-\leftarrow 0-6,6$

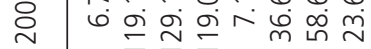

นू 우웋

の

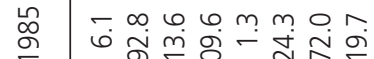

$-\quad \sigma=0-\downarrow N$

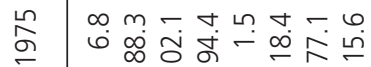

n $\infty \circ \sim \sigma \infty \nabla 6 \forall$

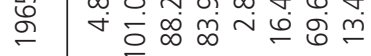

$\frac{0}{0}$




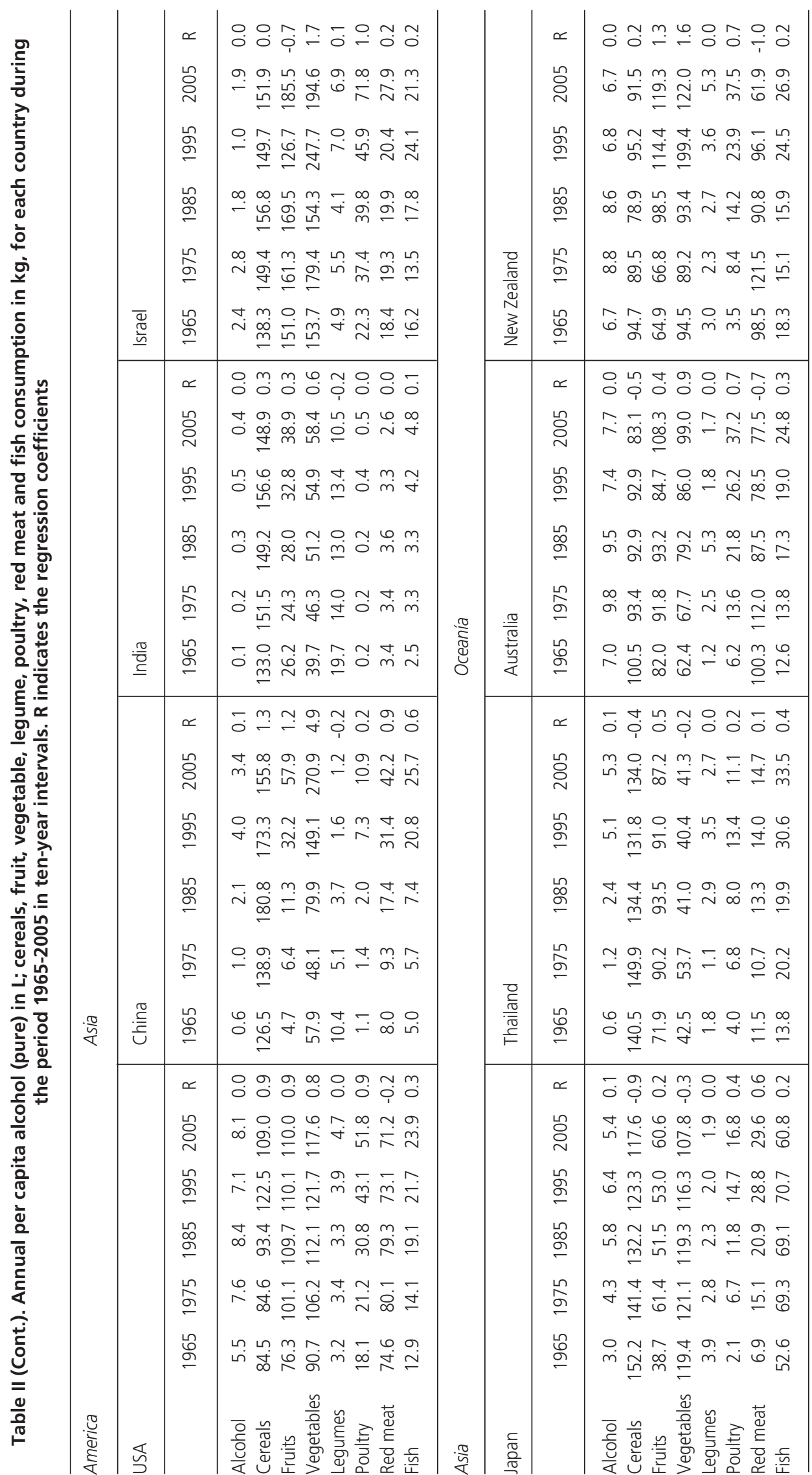


Table III shows Pearson's correlation coefficients between the studied variables according to gender.

In men, correlation coefficients were positive in fourteen of the twenty countries for alcohol consumption, ten for cereals, twelve for fruits, fourteen for vegetables, nine for legumes, seventeen for poultry, seventeen for red meat and twelve for fish.

In women, correlation coefficients were positive in thirteen of the twenty countries for alcohol consumption, nine for cereals, ten for fruits, eleven for vegetables, seven for legumes, thirteen for poultry, nineteen for red meat and eleven for fish.

\section{DISCUSSION}

In this study it has been seen that certain changes in dietary habits may have contributed to the increase in colorectal cancer incidence in Europe.

Important differences in incidence rates according to genders, normally shown as higher values in men (in fifteen countries, incidence rates in men are higher than in women during the period of study), may be the result of a higher exposure to risk factors related to lifestyle, such as dietary habits, or others such as smoking, sedentary lifestyle, overweight, obesity and diabetes.

During the period 1971-2002, four different situations are observed in relation to worldwide colorectal cancer incidence trends:

- Situation 1 (both genders): Brazil, Colombia, Costa Rica, Ecuador (America); India, Thailand (Asia).

- Relatively low incidence rates. Diet: remarkable cereals and fruit consumption (except for India, with scarce fruit intake), legume consumption much higher than in countries in situations 2,3 or 4 (except for Thailand, with similar rates than in those countries) and only slight red meat consumption. Alcohol: scarce consumption.

- Incidence rates with increasing linear trends. Diet: increasing linear trend for red meat consumption in Brazil, Costa Rica, Ecuador and Thailand and decreasing lineal trend for legume consumption in Brazil, Ecuador and India. Alcohol: slightly increasing trends in all countries, especially Brazil and Thailand.

- Situation 2 (both genders): Germany, Italy, Norway, Spain, Sweden (Europe); China, Israel, Japan (Asia); Australia (Oceania).

- High incidence rates. Diet: very scarce legume consumption, high red meat consumption (except for Israel and Japan) and low fish and poultry consumption (except for fish in Norway and Japan and poultry in Israel). Alcohol: notable consumption (except for Israel).

- Incidence rates with increasing linear trends. Diet: increasing linear trend for red meat consumption (except for Australia and Norway) and an important decrease in cereals consumption in countries such as Italy, Spain, Japan and Australia. Alcohol: marked decrease in Italy and notable increases in Norway, Japan and, especially, in China.

- Situation 3: England (Europe); Canada (America).

- High incidence rates. Diet: minimal legume consumption and high red meat consumption. Alcohol: significant intake.

- Incidence rates with increasing linear trends in men and decreasing in women. Diet: decrease in linear trends of red meat consumption, increasing linear trend for fish consumption and slight increase in the consumption of legumes, only in Canada. Alcohol: increasing linear trend in England.

- Situation 4 (both genders): France (Europe); USA (America); New Zealand (Oceania).

- High incidence rates. Diet: minimal legume consumption, high red meat consumption and scarce poultry and fish consumption. Alcohol: significant intake.

- Incidence rates with decreasing linear trends. Diet: notable increase in cereals, fruit, vegetable, poultry and fish consumption (except vegetables for France), marked decreases in the linear trend of red meat consumption in USA and, especially, in New Zealand. Legume consumption remains approximately the same during the period of study. Alcohol: marked decrease in France.

In a recent study carried out in UK the effects of modifying five behavioral risk factors was assessed, including lower red meat consumption, higher fruit and vegetable intake, less than three alcoholic beverages per day in men and two per day in women, thirty minutes of physical exercise five days a week and a strict control of body weight. The study concluded that, these modifications could be responsible for present and further decreases in colorectal cancer rates. This suggest potential benefits in terms of reducing the mortality of this tumor by could be even greater than applying national screening programs or improving treatment options (3).

It is estimated that in median age men, the risk attribution percentage for colorectal cancer due to six risk factors, including red meat consumption, low folic acid intake, alcohol intake, obesity, sedentary lifestyle and youth smoking, is $71 \%$ (4).

Epidemiological evidence has identified different risk and protective factors related to diet for colorectal cancer $(9,10)$, as well as the enormous potential of primary prevention by modifying the exposure to these factors (3-8). The evolution in the consumption of the studied dietary variables may potentially be consistent with the trend in incidence rates in the different studied countries, classifying each one of them in one of the four situations previously described.

In this study, the role of other factors such as smoking, sedentary lifestyle, overweight, obesity and diabetes has not been included. These factors could have contributed to the trends of colorectal cancer observed in this study. 
Table III. Pearson's correlation coefficients of dietary variables compared to annual colorectal cancer incidence rates adjusted to worldwide population per 100,000 inhabitants with a ten-year delay in men and women per country. Alcohol (pure) (L/person/year); cereals, fruits, vegetables, legumes, poultry, red meat, fish (kg/person/year)

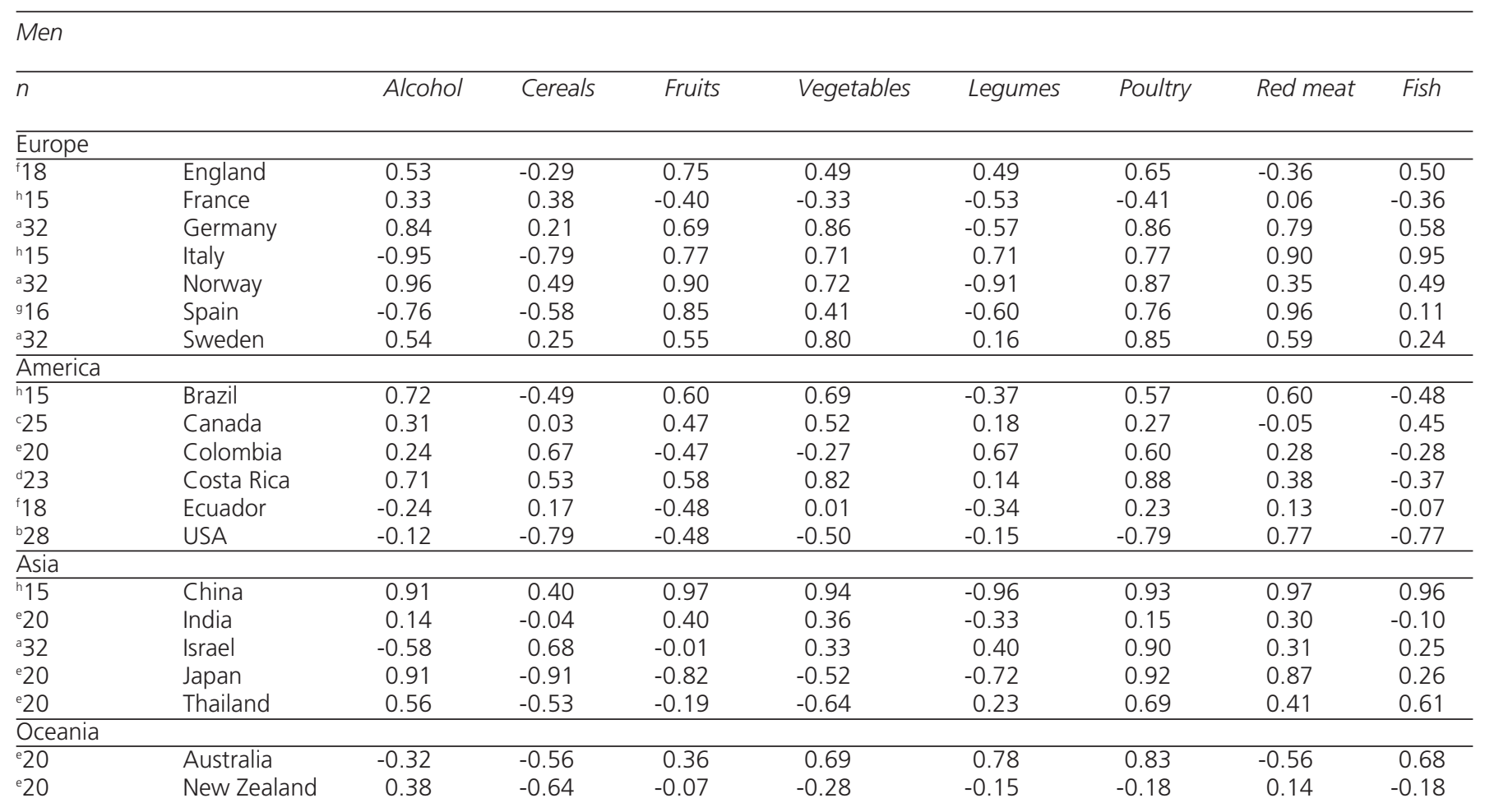

Women

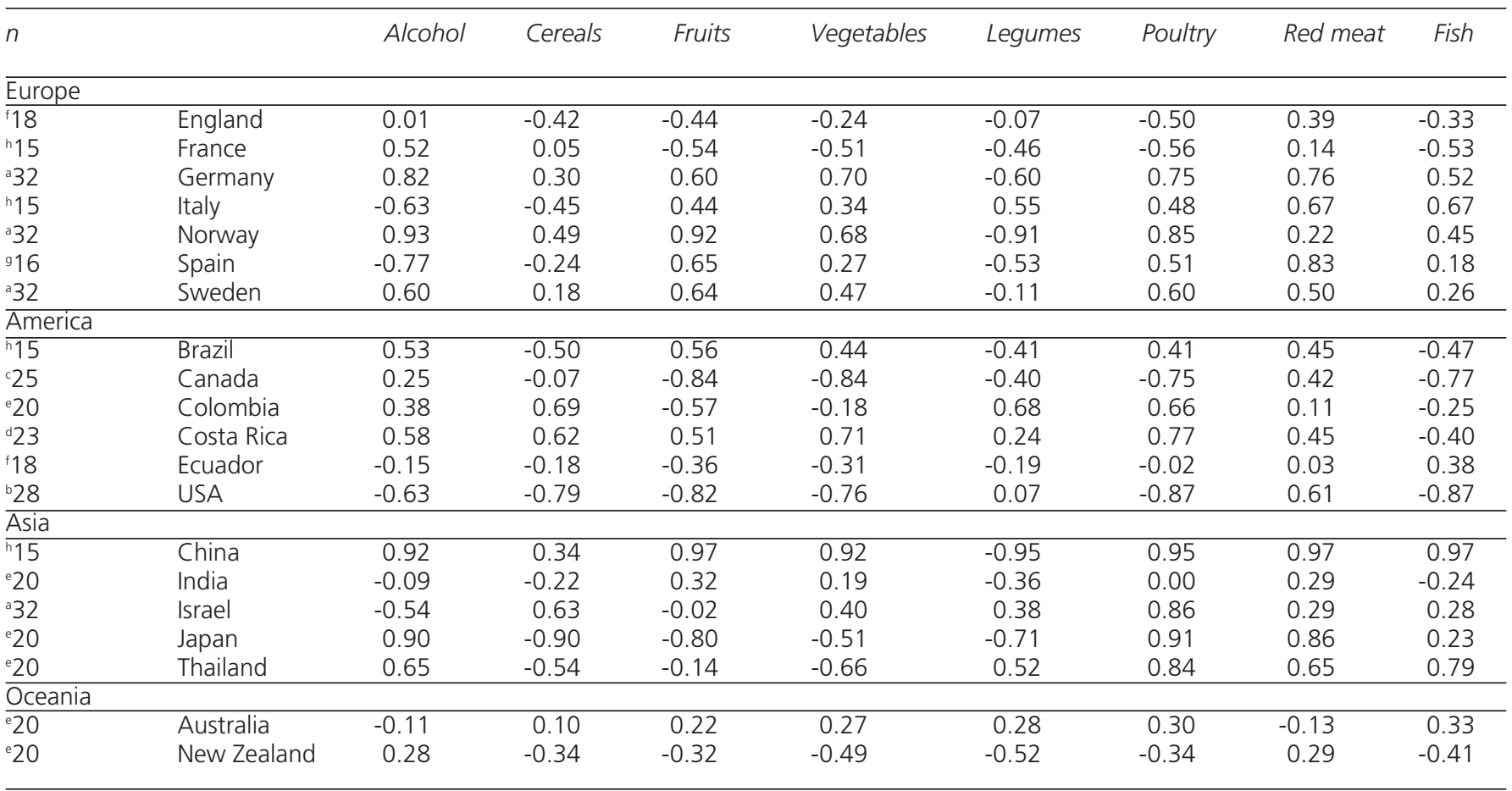

a Comparison of annual consumption during the period 1961-1992 with annual incidence rates during the period 1971-2002. ${ }^{\mathrm{b}} \mathrm{Comparison}$ of annual consumption during the period 1965-1992 with annual incidence rates during the period 1975-2002. 'Comparison of annual consumption during the period $1968-1992$ with annual incidence rates during the period 1978-2002. ${ }^{\circ}$ Comparison of annual consumption during the period 1970-1992 with annual incidence rates during the period $1980-2002$. ${ }^{\circ}$ Comparison of annual consumption during the period 1973-1992 with annual incidence rates during the period 1983-2002. ${ }^{\circ}$ Comparison of annual consumption during the period $1975-$ 1992 with annual incidence rates during the period $1985-2002 .{ }^{9} \mathrm{C}$ omparison of annual consumption during the period $1975-1990$ with annual incidence rates during the period 1985-2000. 'Comparison of annual consumption during the period 1978-1992 with annual incidence rates during the period $1988-2002$. 
The data presented implies that if no preventative measures are taken, the situation in various countries will worsen, passing from situation 1 to 4 , going through intermediate situations 2 and 3. Taking into account the delay of years that is necessary for changes in exposure to risk and protective factors to exert any effect on the incidence of this tumor, and considering demographic, economic, social and cultural characteristics of each country, legislative and educational measure should be adopted in an urgent manner (43) to promote a healthy diet in countries with an emergent socio-economical situation (situation 1) and, for those countries with favourable socio-economical situations (situations 2, 3 or 4), to stop the increasing trends or to maintain the decreasing tendency until reaching the same levels or lower than those observed in countries with situation 1.

\section{REFERENCES}

1. Internacional Agency for Research on Cancer (IARC), 2010. Available at: http://www-dep.iarc.fr/

2. Parkin DM. International variation. Oncogene 2004;23:6329-40.

3. Parkin DM, Olsen AH, Sasieni P. The potential for prevention of colorectal cancer in the UK. Eur J Cancer Prev 2009;18:179-90.

4. Platz EA, Willett WC, Colditz GA, Rimm EB, Spiegelman D, Giovannucci E. Proportion of colon cancer risk that might be preventable in a cohort of middle-aged US men. Cancer Causes Control 2000;11:57988.

5. Moore HG. Colorectal cancer: what should patients and families be told to lower the risk of colorectal cancer? Surg Oncol Clin N Am 2010;19:693-710.

6. de Vries E, Soerjomataram I, Lemmens VE, Coebergh JW, Barendregt $\mathrm{JJ}$, Oenema A, et al. Lifestyle changes and reduction of colon cancer incidence in Europe: A scenario study of physical activity promotion and weight reduction. Eur J Cancer 2010;46:2605-16.

7. Gonzalez CA, Riboli E. Diet and cancer prevention: Contributions from the European Prospective Investigation into Cancer and Nutrition (EPIC) study. Eur J Cancer 2010;46:2555-62.

8. Lance P, Hamilton SR. Sporadic aberrant crypt foci are not a surrogate endpoint for colorectal adenoma prevention. Cancer Prev Res 2008;1:48 .

9. Franco A, Sikalidis AK, Solis Heruzo JA. Colorectal cancer: influence of diet and lifestyle factors. Rev Esp Enferm Dig 2005;97:432-48.

10. Rodrigo L, Riestra S. Diet and colon cancer. Rev Esp Enferm Dig 2007:99:183-9.

11. Solera Albero J, Tárraga López PJ, Carbayo Herencia JA, López Cara MA, Celada Rodríguez A, Cerdán Oliver M, et al. Influence of diet and lifestyle in colorectal cancer. Rev Esp Enferm Dig 2007;99:190200.

12. Cho E, Smith-Warner SA, Ritz J, van den Brandt PA, Colditz GA, Folsom AR, et al. Alcohol intake and colorectal cancer: a pooled analysis of 8 cohort studies. Ann Intern Med 2004;140:603-13.

13. Sandhu MS, White IR, McPherson K. Systematic review of the prospective cohort studies on meat consumption and colorectal cancer risk: a meta-analytical approach. Cancer Epidemiol Biomarkers Prev 2001:10:439-46.

14. English DR, MacInnis RJ, Hodge AM, Hopper JL, Haydon AM, Giles GG. Red meat, chicken, and fish consumption and risk of colorectal cancer. Cancer Epidemiol Biomarkers Prev 2004;3:1509-14.

15. Norat T, Bingham S, Ferrari P, Slimani N, Jenab M, Mazuir M, et al. Meat, fish, and colorectal cancer risk: the European Prospective Investigation into Cancer and Nutrition. J Natl Cancer Inst 2005;97:906-16.

16. Zell JA, Ziogas A, Bernstein L, Clarke CA, Deapen D, Largent JA, et al. Meat consumption, nonsteroidal anti-inflammatory drug use, and mortality among colorectal cancer patients in the California Teachers Study. Cancer Prev Res 2010;3:865-75.
17. Terry P, Giovannucci E, Michels KB, Bergkvist L, Hansen H, Holmberg $\mathrm{L}$, et al. Fruit, vegetables, dietary fiber, and risk of colorectal cancer. J Natl Cancer Inst 2001;93:525-33.

18. Riboli E, Norat T. Epidemiologic evidence of the protective effect of fruit and vegetables on cancer risk. Am J Clin Nutr 2003;78:559-69.

19. Botteri E, Iodice S, Bagnardi V, Raimondi S, Lowenfels AB, Maisonneuve P. Smoking and colorectal cancer: a meta-analysis. JAMA 2008;300:2765-78.

20. Botteri E, Iodice S, Raimondi S, Maisonneuve P, Lowenfels AB. Cigarette smoking and adenomatous polyps: a meta-analysis. Gastroenterology 2008;134:388-95.

21. Giovannucci E. An updated review of the epidemiological evidence that cigarette smoking increases risk of colorectal cancer. Cancer Epidemiol Biomarkers Prev 2001;10:725-31.

22. World Cancer Research Fund / American Institute for Cancer Research Policy and action for cancer prevention. Food, nutrition, and physical activity: a global perspective. Washington DC: AICR; 2009.

23. Pischon T, Lahmann PH, Boeing H, Friedenreich C, Norat T, Tjønneland A, et al. Body size and risk of colon and rectal cancer in the European Prospective Investigation into Cancer and Nutrition (EPIC). J Natl Cancer Inst 2006;98:920-31

24. Larsson SC, Wolk A. Obesity and colon and rectal cancer risk: a metaanalysis of prospective studies. Am J Clin Nutr 2007;86:556-65.

25. Larsson SC, Orsini N, Wolk A. Diabetes mellitus and risk of colorectal cancer: a meta-analysis. J Natl Cancer Inst 2005;97:1679-87.

26. Thompson CL, Larkin EK, Patel S, Berger NA, Redline S, Li L. Short duration of sleep increases risk of colorectal adenoma. Cancer. Forthcoming 2010. 2011;117(4):841-7.

27. Grodstein F, Newcomb PA, Stampfer MJ. Postmenopausal hormone therapy and the risk of colorrectal cancer: a review and meta-analysis Am J Med 1999;106:574-82

28. Protiva P, Cross HS, Hopkins ME, Kállay E, Bises G, Dreyhaupt E, et al. Chemoprevention of colorectal neoplasia by estrogen: potential role of vitamin D activity. Cancer Prev Res 2009;2:43-51.

29. Fernandez E, La Vecchia C, Balducci A, Chatenoud L, Franceschi S, Negri E. Oral contraceptives and colorrectal cancer risk: a meta-analysis. Br J Cancer 2001;84:722-7.

30. Cho E, Smith-Warner SA, Spiegelman D, Beeson WL, van den Brand PA, Colditz GA, et al. Dairy foods, calcium, and colorectal cancer: a pooled analysis of 10 cohort studies. J Natl Cancer Inst 2004;96:101522.

31. Nock NL, Patrick-Melin A, Cook M, Thompson C, Kirwan JP, Li L. Higher bone mineral density is associated with a decreased risk of colorectal adenomas. Int J Cancer 2011;129(4):956-64.

32. Colditz GA, Cannuscio CC, Frazier AL. Physical activity and reduced risk of colon cancer: implications for prevention. Cancer Causes Control 1997:8:649-67.

33. Colditz GA, Samplin-Salgado M, Ryan CT, Dart H, Fisher L, Tokuda A, et al.; Harvard Report on Cancer Prevention. Volume 5. Fulfilling the potential for cancer prevention: policy approaches. Cancer Causes Control 2002;13:199-212.

34. Wolin KY, Yan Y, Colditz GA, Lee IM. Physical activity and colon cancer prevention: a meta-analysis. Br J Cancer 2009;100:611-6.

35. Bingham SA, Day NE, Luben R, Ferrari P, Slimani N, Norat T, et al. Dietary fibre in food and protection against colorectal cancer in the European Prospective Investigation into Cancer and Nutrition (EPIC): an observational study. Lancet 2003; 361: 1496-501.

36. Park Y, Hunter DJ, Spiegelman D, Bergkvist L, Berrino F, van den Brandt PA, et al. Dietary fiber intake and risk of colorectal cancer: a pooled analysis of prospective cohort studies. JAMA 2005;294:284957.

37. Alberts DS, Martinez ME, Roe DJ, Guillén-Rodríguez JM, Marshall JR, van Leeuwen JB, et al. Lack of effect of a high-fiber cereal supplement on the recurrence of colorectal adenomas. Phoenix Colon Cancer Prevention Physicians' Network. N Engl J Med 2000;342:115662.

38. Schatzkin A, Lanza E, Corle D, Lance P, Iber F, Caan B, et al. Lack of effect of a low-fat. highfiber diet on the recurrence of colorectal adenomas. Polyp Prevention Trial Study Group. N Engl J Med 2000; 342:1149-55.

39. Baron JA. Dietary fiber and colorectal cancer: an ongoing saga. JAMA 2005;294:2904-06. 
40. Howe GR, Aronson KJ, Benito E, Castelleto R, Cornée J, Duffy S, et al. The relationship between dietary fat intake and risk of colorectal cancer -evidence from the combined analysis of 13 case-control studies. Cancer Causes Control 1997;8:215-28.

41. Willett WC. Goals for nutrition in the year 2000. Cancer J Clin 1999; 49:331-52.
42. Food and Agriculture Organization of United Nations. FAOSTAT. Crops primary equivalent and livestock and fish primary equivalent consumption statistics, 2010. Available at: http://faostat.fao.org/

43. Bejar L, Gili M, Ramírez G, López J, Cabanillas JL. Dietary changes and colorectal cancer trends in Spain during 1951-2007. Rev Esp Enferm Dig 2010;102:159-68. 